\title{
ANALISA KINERJA PERSIMPANGAN TAK BERSINYAL TIPE T PADA PERTEMUAN RUAS JALAN TIMOR RAYA DAN JALAN SURATIM DI KELURAHAN OESAPA KECAMATAN KELAPA LIMA KOTA KUPANG PROVINSI NUSA TENGGARA TIMUR
}

\author{
Koilal Alokabel ${ }^{1}$ \\ ${ }^{1}$ Dosen Jurusan Teknik Sipil Politeknik Negeri Kupang \\ Jl. Adi Sucipto, Penfui, KIp. Lima, Kota Kupang, Nusa Tenggara Timur \\ E-mail: koilal.alokabel@pnk.ac.id
}

\begin{abstract}
Abstrak
Persimpangan sebagai salah satu tempat pertemuan ruas-ruas jalan dan tempat kendaraan melakukan perubahan arah pergerakan arah lalu lintas. Persimpangan dapat bervariasi dari persimpangan sederhana yang terdiri dari pertemuan dua ruas jalan sampai persimpangan kompleks yang terdiri dari pertemuan beberapa ruas jalan. Namun dengan tingkat pergerakan yang beragam dari berbagai jenis kendaraan, mengakibatkan kendaraan pada persimpangan, akan mengalami tundaan perjalanan yang cukup besar, sehingga biaya perjalanan akan menjadi lebih besar pula. Tidak dapat dibayangkan berapa banyak uang yang terbuang percuma karena kendaraan terperangkap dalam kemacetan dan berapa banyak uang yang dapat disimpan jika kemacetan dapat dihilangkan (dari segi biaya bahan bakar dan nilai waktu tundaan). Hal tersebut menyebabkan perlu dipikirkan beberapa alternatif pemecahan masalah transportasi. Faktor lain penyebab kemacetan adalah meningkatnya kecenderungan para pemakai jasa transportasi untuk menggunakan kendaraan pribadi dibandingkan dengan kendaraan umum. Akibat lebih jauh dari kecenderungan ini adalah menurunnya efisiensi penggunaan sarana maupun prasarana jaringan jalan yang semakin mempersulit upaya penanggulangan kemacetan. Hasil analisa kinerja persimpangan pada kondisi jam puncak (07.00-08.00 WITA) saat itu tidak mampu menampung jumlah kendaraan yang lewat, karena dari beberapa parameter yang dianalisis untuk menentukan tingkat kinerja persimpangan pada kondisi saat ini tidak memenuhi, seperti kapasitas 1964 smp/jam, derajat kejenuhan 1,16, tundaan total rata-rata 28,46 detik/smp, tundaan rata-rata jalan utama $17,61 \mathrm{detik} / \mathrm{smp}$, tundaan rata-rata jalan minor 66,44 detik/smp, tundaan geometrik simpang adalah 3 , tundaan simpang 31,46 detik/smp dan peluang antrian 54,62-110,28 \%. Analisa terhadap nilai tundaan 31,46 detik/smp maka tingkat kinerja pada kondisi simpang saat ini dikategorikan dalam tingkat pelayanan D. Untuk meningkatkan kinerja persimpangan maka dilakukan pengaturan lalu lintas dengan lampu lalu lintas (traffic light). Peningkatan kinerja simpang tersebut dapat juga ditempuh dengan pelebaran lajur, menambah lajur ataupun memperlebar jalan.
\end{abstract}

Kata kunci: Persimpangan, lalu lintas.

\section{PENDAHULUAN}

Simpang antara ruas Jalan Timor Raya dan Jalan Suratim telah menunjukkan kondisi arus lalu lintas yang cukup padat yang disebabkan oleh fungsi jalan dan fungsi lahan. Jalan Timor Raya merupakan jalan arteri yang mempunyai volume lalu lintas yang tinggi jika dibandingkan dengan Jalan Suratim yang merupakan jalan penghubung. Fungsi lahan yang merupakan daerah dimana lalu lintas cukup padat seperti adanya Puskesmas, daerah permukiman, tempat peribadatan (Gereja), PAUD dan SD, sehingga perlu perbaikan kinerja simpang tersebut agar penguna jalan dapat berlalu lintas dengan aman dan nyaman.

\section{Tujuan Penelitian}

Tujuan dari penelitian ini adalah mengetahui tingkat pelayanan simpang tak bersinyal pada ruas Jalan Timor Raya dan Jalan Suratim dan Mengendalikan agar persimpangan tersebut dapat memberikan pelayanan yang lebih baik terhadap arus lalu lintas.

\section{Manfaat Penelitian}

Manfaat penelitian ini adalah sebagai pengembangan ilmu rekayasa lalu lintas dan dapat dipakai sebagai bahan masukan oleh instansi terkait dalam mengambil kebijakan penanganan permasalahan yang terjadi di persimpangan. 


\section{TINJAUAN PUSTAKA}

\section{Persimpangan Jalan (Intersection)}

Persimpangan jalan adalah daerah atau tempat dimana jalan-jalan bertemu dan lintasan kendaraan berpotongan. Lalu lintas pada masing-masing kaki persimpangan menggunakan ruang jalan pada persimpangan secara bersama-sama dengan lalu lintas lainnya, (Abubakar,dkk; 1999:31). Masalah utama (yang saling kait mengait) pada persimpangan adalah, Volume dan kapasitas yang secara langsung mempengaruhi tundaan, Terdapat 4 jenis dasar alih gerak kendaraan (Abubakar, dkk;1999:31), yaitu : Gerakan berpencar (diverging), Gerakan penggabungan ( merging, Gerakan berpotongan (crossing), Gerakan persilangan (weaving

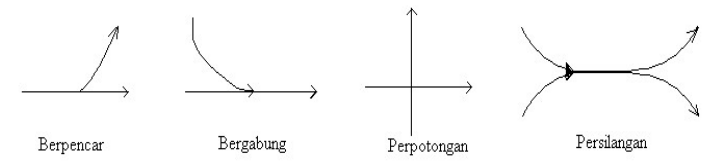

Gambar 1. Arah pergerakan kendaraan

\section{Geometrik Persimpangan}

Menurut Nawawi, dkk (1992:220) menjelaskan bahwa kondisi geometrik persimpangan seperti : jalur, kemiringan atau marka menjadi variabel penting dalam analisis kinerja suatu persimpangan tanpa lampu lalu lintas. Kondisi geometrik persimpangan yang dijadikan parameter adalah, Jumlah jalur dan arah, Lebar jalur, Kelandaian pada simpang, Jumlah lajur, Lebar jalur jalan, Lebar bahu jalan, Lebar efektif, Median.

\section{Volume Lalu lintas}

Anonimus (1997:2-6) menjelaskan volume lalu lintas adalah jumlah kendaraan dalam satuan mobil penumpang (smp) yang melewati suatu potongan ruas jalan yang dihitung dalam satuan waktu tertentu, misalnya 5 menit, 15 menit, 30 menit , 1 jam, 1 hari dan sebagainya, dengan klasifikasi kendaraan digolongkan dalam 4 jenis yaitu, Kendaraan berat, Kendaraan ringan, Sepeda motor, Kendaraan tak bermotor.

Tabel.1. Ekivalen Jenis Kendaraan

\begin{tabular}{ccc}
\hline No & Jenis Kendaraan & $\begin{array}{c}\text { Nilai } \\
\text { Ekivalen } \\
(\mathrm{emp})\end{array}$ \\
\hline 1 & Mobil Penumpang dan & 1.0 \\
2 & Kendaraan Ringan (LV) & 0.5 \\
3 & Sepeda Motor (MC) & 1.3 \\
4 & Kendaraan Berat (HV) & - \\
\hline
\end{tabular}

Sumber: Anonimus (1997:2-7)

\section{Tipe Simpang}

Tipe simpang menentukan banyaknya lengan simpang dan banyaknya lajur pada jalan utama dan jalan simpang tersebut dengan kode tiga angka, dan dapat diuraikan pada Tabel berikut ini:

Tabel 2. Tipe Simpang

\begin{tabular}{cccc}
\hline Kode IT & $\begin{array}{c}\text { Jumlah } \\
\text { Lengan } \\
\text { Simpang }\end{array}$ & $\begin{array}{c}\text { Jumlah Lajur } \\
\text { Jalan } \\
\text { Simpang }\end{array}$ & $\begin{array}{c}\text { Jumlah } \\
\text { Lajur } \\
\text { Jalan } \\
\text { Utama }\end{array}$ \\
\hline 322 & 3 & 2 & 2 \\
324 & 3 & 2 & 4 \\
342 & 3 & 4 & 2 \\
422 & 4 & 2 & 2 \\
424 & 4 & 2 & 4 \\
444 & 4 & 4 & 4 \\
\hline
\end{tabular}

Sumber: Anonimus (1997:3-31)

Tingkat Pelayanan Jalan

Menurut Alik Ansyori (2005:65) mengatakan bahwa tingkat pelayanan jalan adalah kondisi operasional dalam arus lalu lintas yang penilaiannya oleh pemakai jalan (pada umumnya dinyatakan dalam kecepatan, waktu tempuh, kebebasan bergerak, interupsi lalu lintas, kenyamanan dan keselamatan). Anonimus (1997:1-7) juga menjelaskan bahwa tingkat pelayanan jalan dapat dihitung berdasarkan lamanya tundaan (D) pada simpang tersebut, untuk lebih jelasnya dapat dilihat pada tabel berikut ini:

Tabel 3. Kategori Tingkat Pelayanan Simpang

\begin{tabular}{|c|c|}
\hline $\begin{array}{c}\text { Tingkat } \\
\text { Pelayanan }\end{array}$ & Tundaan rata-rata (det) \\
\hline A & $\leq 0.5$ \\
\hline B & $5.1-15.0$ \\
\hline C & $15.1-25.0$ \\
\hline D & $25.1-40.0$ \\
\hline$E$ & $40.1-60$ \\
\hline$F$ & $>60$ \\
\hline \multicolumn{2}{|c|}{$\begin{array}{l}\text { Sumber : Anonimus (1985:15-1). } \\
\text { Metode Pengendalian Persimpangan } \\
\text { Menurut Abubakar, dkk (19 }\end{array}$} \\
\hline
\end{tabular}


pergerakan kendaraan diperlukan agar kendaraan yang melakukan gerakan konflik tersebut tidak akan saling bertabrakan. Konsep yang utama dalam pengendalian persimpangan adalah prioritas, yaitu suatu aturan untuk menentukan kendaraan mana yang dapat berjalan lebih dahulu, sistem pengendalian ini didasarkan atas prinsipprinsip tertentu, yaitu: Aturan prioritas harus secara jelas dimengerti oleh pengemudi atau pengendara, Prioritas harus terbagi dengan baik, sehingga setiap orang mempunyai kesempatan untuk bergerak, Prioritas harus terorganisasi, sehingga titik-titik konflik dapat diperkecil, Keputusan-keputusan yang dilakukan oleh pengemudi harus dijaga sederhana mungkin, Jumlah hambatan total terhadap lampu lalu lintas sekecil mungkin.

\section{METODE PENELITIAN}

\section{Tahapan Penelitian}

Tahapan penelitian ini dapat di jelaskan dalam bagan alir ini,

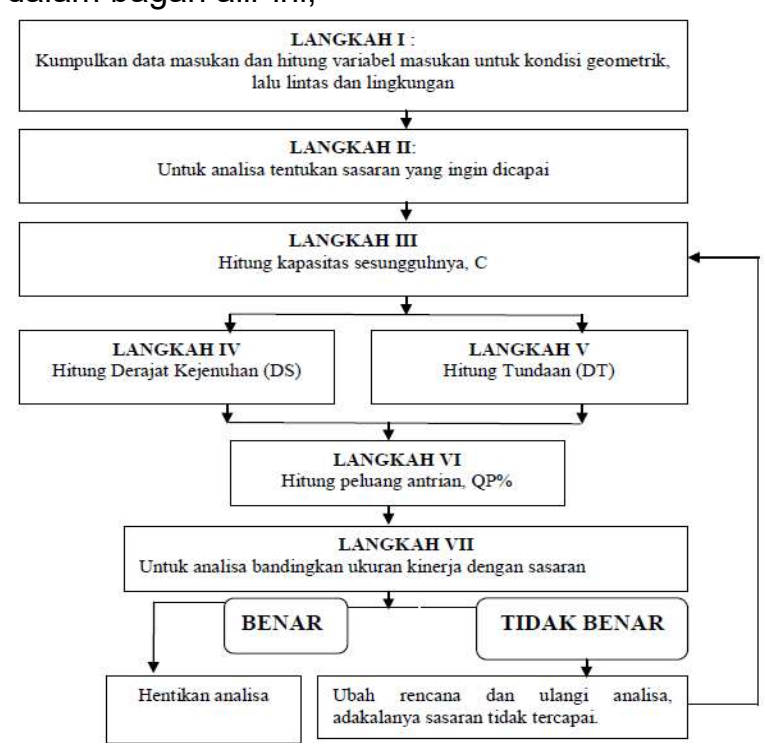

Gambar 1. Bagan alir penelitian

\section{Lokasi Penelitian}

Lokasi Penelitian ini merupakan lokasi yang padat kendaraan karena ada pertemuan simpang, dapat ditunjukan pada gambar berikut ini,

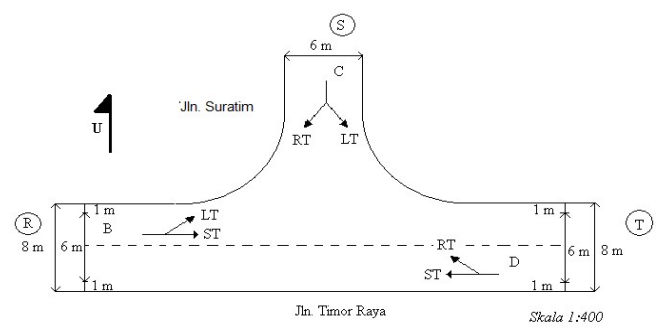

Gambar 2. Denah lokasi penelitian dan arah pergerakan kendaraan

Keterangan:

$\rightarrow \quad:$ Arah pergerakan kendaraan

C (RT) : Arah pergerakan kendaraan pada pendekat $\mathrm{C}$ dengan arah pergerakan kendaraan dari Suratim ke Timor Raya (belok kanan).

C (LT) : Arah pergerakan kendaraan pada pendekat $\mathrm{C}$ dengan arah pergerakan kendaraan dari Suratim ke Kupang (belok kiri).

D (RT) : Arah pergerakan kendaraan pada pendekat $\mathrm{D}$ dengan arah pergerakan kendaraan dari Kupang ke Suratim (belok kanan).

D (ST) : Arah pergerakan kendaraan pada pendekat $D$ dengan arah pergerakan kendaraan dari Kupang ke Lasiana (lurus).

B (ST) : Arah pergerakan kendaraan pada pendekat B dengan arah pergerakan kendaraan dari Oesapa ke Kupang (lurus).

B (LT) : Arah pergerakan kendaraan pada pendekat $C$ dengan arah pergerakan kendaraan dari Lasiana ke Suratim (belok kiri).

\section{$\mathrm{R}, \mathrm{S}, \mathrm{T} \quad$ : Pendekat jalan}

\section{Waktu Pelaksanaan Survey}

Kenyataan yang terjadi, adanya variasi dari arus lalu lintas di lokasi persimpangan dalam satu hari dimana adakalanya sepi dan padat, maka pengambilan data lalu lintas dilakukan pada jam-jam sibuk pada pagi, siang hari dan sore hari. Hasil pengamatan visual terhadap persimpangan yang diteliti, menunjukkan bahwa pengambilan data arus lalu lintas di persimpangan untuk mendapatkan arus jenuh direncanakan pada jam-jam puncak. Jam puncak pagi hari dimulai pada jam 06.00 - 09.00 WIT dan pada siang hari dimulai jam $12.00-15.00$ WIT dan sore hari dari pukul 17.00 - 19.00 WIT. 


\section{Pengolahan Data}

Pengolahan data merupakan pekerjaan proses awal untuk menilai kinerja persimpangan. Langkah-langkah dalam pengolahan data adalah sebagai berikut :

1. Mengumpulkan formulir survey arus lalu lintas

2. Menjumlahkan arus lalu lintas tiap arah untuk dijadikan volume lalu lintas tiap jam, untuk masing-masing jenis kendaraan dan pendekat

3. Mengkonversikan data jumlah lalu lintas ke dalam satuan mobil penumpang (smp) untuk tiap pendekat.

4. Menghitung rasio kendaraan tak bermotor (PUM), rasio kendaraan belok kiri (PLT) dan rasio kendaraan belok kanan

5. Menyusun data-data tersebut untuk perhitungan selanjutnya.

\section{HASIL DAN PEMBAHASAN}

Hasil dan pembahasan untuk kinerja persimpangan Jalan Timor Raya dan Jalan Suratim dapat di sajikan dalam tabel berikut ini,

Tabel 4. Hasil analisa simpang tak bersinyal untuk kondisi saat ini.

\begin{tabular}{ccc}
\hline No & Komponen Analisa & $\begin{array}{c}\text { Hasil } \\
\text { perhitungan }\end{array}$ \\
\hline 1 & Kapasitas (smp/jam) & 1964 \\
2 & Derajat kejenuhan & 1,16 \\
3 & $\begin{array}{c}\text { Tundaan total rata-rata } \\
\text { (detik/smp) }\end{array}$ & 28,46 \\
4 & $\begin{array}{c}\text { Tundaan rata-rata jalan } \\
\text { utama (detik/smp) }\end{array}$ & 17,61 \\
& 66,44 \\
5 & $\begin{array}{c}\text { Tundaan rata-rata jalan } \\
\text { minor (detik/smp) }\end{array}$ & 3 \\
& Tundaan geometrik & 31,46 \\
6 & simpang (detik/smp) & $54,62-$ \\
7 & Tundaan simpang & 110,28 \\
8 & (detik/smp) & \\
& Peluang antrian (\%) &
\end{tabular}

Sumber : Hasil analisa (2017)

Gambar 1. Grafik hubungan antara x dan xx

Hasil analisa menunjukan bahwa kinerja simpang kondisi saat ini dengan pengaturan arus simpang tak bersinyal tidak efektif karena hasil analisa beberapa parameter tidak memenuhi persyaratan terutama derajat kejenuhan (DS) yang didapat telah melebihi DS = 0,75 (Anonimus, 1997: 340). Hasil analisa kinerja simpang pada jam puncak, dimana arus lalu lintas total yang masuk simpang 2277 smp/jam, dengan memberikan nilai kapasitas 1964 smp/jam, derajat kejenuhan (DS) 1,16, tundaan rata-rata simpang sebesar 28,46 detik/smp, total tundaan simpang 31,46 detik/smp dan probabilitas antrian $54,62-110,28 \%$. Untuk fluktuasi kenderaan pada pada jam-jam sibuk dapat di lihat pada grafik berikut ini,

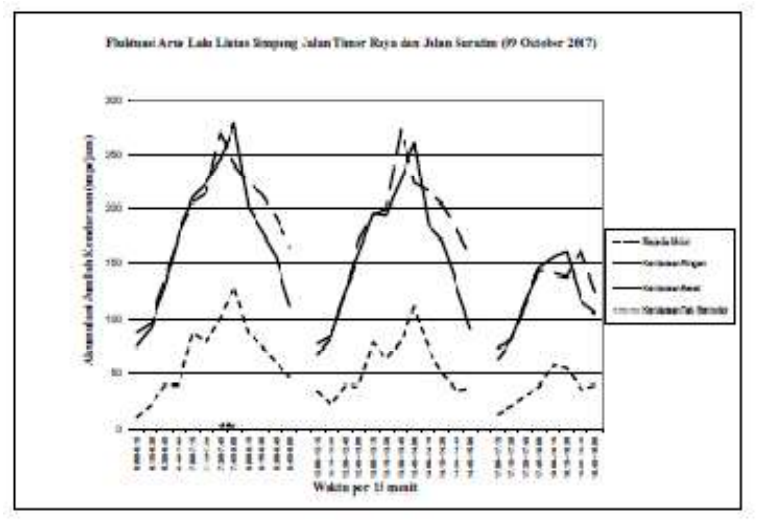

Gambar 1. Arus Fluktuasi Kenderaan pada tanggal 09 Oktober 2017

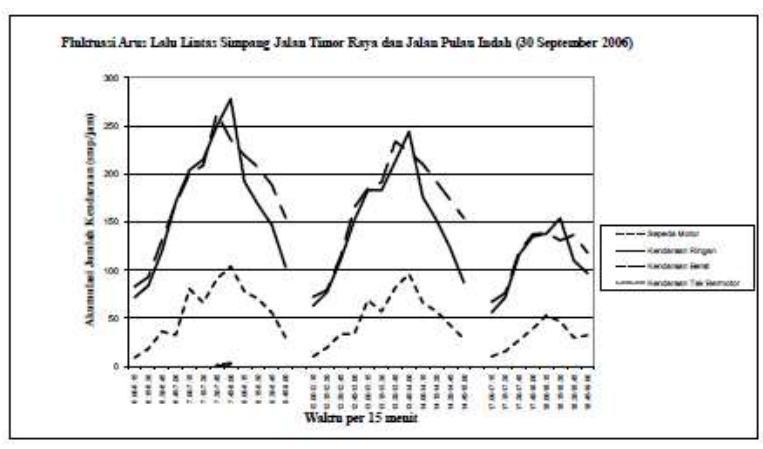

Grafik 1. Arus Fluktuasi Kenderaan pada tanggal 07 Oktober 2017

\section{Analisa Tingkat Pelayanan Jalan}

Hasil analisa pada kondisi saat ini melalui beberapa parameter diatas maka menurut Anonimus (1997: 15-1) tingkat pelayanan di simpang tersebut dikategorikan dalam tingkat pelayanan $\mathrm{D}$. Tingkat pelayanan $D$ ini dengan ciri-ciri:

1. Arus mendekati tidak stabil dengan volume lalu lintas tinggi dan kecepatan masih ditolerir namun sangat terpengaruh oleh perubahan kondisi arus;

2. Kepadatan lalu lintas sedang namun fluktuasi volume lalu lintas dan hambatan temporer dapat menyebabkan penurunan kecepatan yang besar;

3. Pengemudi memiliki kebebasan yang 
sangat terbatas dalam menjalankan kendaraan, kenyamanan rendah, tetapi kondisi ini masih dapat ditolerir untuk waktu yang singkat.

\section{Metode Pengendalian Persimpangan}

Ada tiga macam metode pendekatan pengendalian pergerakan kendaraan pada persimpangan yang dapat dipergunakan, Pembagian ruang (space sharing), pembagian ruang secara bersama-sama seperti bundaran lalu lintas (round bouts), Pembagian waktu (time sharing), penggunaan waktu secara bersama-sama yang diterapkan dengan lampu-lampu pengatur lalu lintas, Pemisahan bidang pada persimpangan secara overpass, dan underpass.

Hasil analisa menunjukan bahwa tundaan di simpang adalah 31,46 detik/smp ini menunjukan bahwa kondisi arus lalu lintas di simpang sudah mulai buruk, untuk lebih efesien dan efektif maka simpang tersebut sudah dapat dipasang suatu isyarat untuk dapat meningkatkan kinerja dari suatu simpang tersebut. Peningkatan arus kendaraan ini harus dibarengi oleh suatu pengendalian persimpangan, untuk itu perlu adanya alat pemberi isyarat (lampu lalu lintas) agar bisa mengendalikan pergerakan kendaraan.

\section{PENUTUP}

Berdasarkan hasil pengamatan dan analisa serta berdasarkan perumusan masalah, tujuan dan hasil pembahasan yang telah dipaparkan di depan maka dapat disimpulkan sebagai berikut.

a. Hasil analisa kinerja persimpangan pada kondisi jam puncak (07.00-08.00 WITA) saat itu tidak mampu menampung jumlah kendaraan yang lewat, karena dari beberapa parameter yang dianalisis untuk menentukan tingkat kinerja persimpangan pada kondisi saat ini tidak memenuhi, seperti kapasitas 1964 smp/jam, derajat kejenuhan 1,16 , tundaan total rata-rata 28,46 detik/smp, tundaan rata-rata jalan utama $17,61 \mathrm{detik} / \mathrm{smp}$, tundaan rata-rata jalan minor 66,44 detik/smp, tundaan geometrik simpang adalah 3 , tundaan simpang 31,46 detik/smp dan peluang antrian 54,62 - 110,28 \%. Analisa terhadap nilai tundaan $31,46 \mathrm{detik} / \mathrm{smp}$ maka tingkat kinerja pada kondisi simpang saat ini dikategorikan dalam tingkat pelayanan $D$. b. Untuk meningkatkan kinerja persimpangan maka dilakukan pengaturan lalu lintas dengan lampu lalu lintas (traffic light). Peningkatan kinerja simpang tersebut dapat juga ditempuh dengan pelebaran lajur, menambah lajur ataupun memperlebar jalan.

Rekomendasi yang dapat di berikan melalui penelitian ini adalah,

a. Pemerintah Kota Kupang khususnya Dinas terkait sesegera mungkin memasang lampu lalu lintas dan memperbaiki geometrik simpang pada pertemuan ruas Jalan Timor Raya dan Jalan Suratim agar dapat mengatasi masalah yang terkait apa yang yang telah dianalisis.

b. Volume kendaraan yang masuk keluar simpang cukup tinggi maka diharapkan pada instansi terkait dapat membatasi pergerakan kendaraan, misalnya kendaraan roda dua (khususnya sepeda motor) atau membuat alternatif jalan lain untuk mengurangi kepadatan arus lalu lintas.

c. Akademis diharapkan dapat meningkatkan peran aktifnya dalam memberikan masukan guna penanganan masalah lalu lintas lebih dini.

\section{DAFTAR PUSTAKA}

Abubakar I, dkk, 1998, Sistem Transportasi Kota. Direktorat Jenderal Perhubungan Darat, Jakarta. 1999, Rekayasa Lalu Lintas. Direktorat Jenderal Perhubungan Darat, Jakarta.

Alamsyah A.A, 2005, Rekayasa Lalu Lintas, Universitas Muhammadiyah, Malang.

Anonimus, 1997, Manual Kapasitas Jalan Indonesia. PT. Bina Karya, Jakarta.

Internet (http. www. Google.com), 2016, Nusa Tenggara Timur Dalam Angka, BPS Kota Kupang 